\title{
Key factors for the implementation and integration of innovative ICT solutions in SMEs and large companies involved in the multimodal transport of dangerous goods
}

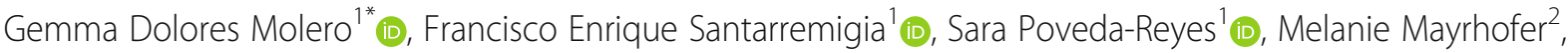 \\ Samir Awad-Núñez ${ }^{3}$ (D) and Abdullah Kassabji ${ }^{4}$
}

\begin{abstract}
The increased number of transports with dangerous goods (TDG) increases the risk of both accidents and terrorist attacks. Digitalisation is crucial in order to avoid human errors and to increase safety, security and efficiency, however there are few research studies that analyse digitalisation for the TDG, this being the first time, to the author's knowledge, that barriers to the implementation of information and communication technology (ICT) solutions for the transport of dangerous goods has been analysed. A new elicitation methodology called the 'implementation acceleration methodology for ICT (IAM-ICT)' has been created, with the aim of identifying and hierarchizing potential barriers to the implementation and integration of ICT solutions involved in the multimodal TDG, and with a view to overcoming the most relevant problems at an early stage. This methodology combines user-driven innovation (UDI), the analytic hierarchy process (AHP) and Bayesian networks. The application of this methodology, which is easily replicable in other fields, will enable a better design of ICT solutions so that they can be implemented and integrated in SMEs and large companies. The results show a hierarchy of potential barriers for a multi-modular ICT solution used as use case study, in two different co-designed schemes for a small and medium enterprise (SME) and for a large company.
\end{abstract}

Keywords: ICT implementation, Supply chain management, Digitalisation, Transport of dangerous goods, Bayesian networks, Analytic hierarchy process (AHP), User-driven innovation (UDI)

\section{Introduction}

The transport of dangerous goods (TDG) has been increasing in recent years. In 2015, the road freight transport of dangerous goods in Europe moved around 82 billion tonne-kilometres, which represented an $8.8 \%$ increase compared with 2014 [1] and $€ 615$ billion of sales [2]. This rise in the TDG increases the risk of accidents. The most recent European data for road transport shows that $19.73 \%$ of checked transport units in 2014 had at least one infringement, with $27.72 \%$ of the infringements also requiring the vehicle to be immobilised [3]. Moreover, $42.69 \%$ of the infringements were classified as very

\footnotetext{
* Correspondence: gmolero@aitec-intl.com

${ }^{1}$ AITEC, Parque Tecnológico, C/ Charles Robert Darwin, 20, Paterna, 46980

Valencia, Spain

Full list of author information is available at the end of the article
}

serious: the transport did not comply with relevant safety provisions, thereby creating a high-level risk of death, serious personal injury or significant damage to the environment (data from 2012) [3]. This data shows that despite current legislation in this field, human errors can always occur.

The TDG has become a highly regulated field due to their hazardous characteristics. There are various standardised European codes, as well as national regulations. The variety of regulations makes compliance with all safety and documentation requirements difficult, which leads to human mistakes, and demonstrates the need for digitalisation and automation through ICT.

ICT brings multiple benefits to organisations by providing high visibility, control and efficient data exchange across the supply chain, as well as better flexibility in reacting to 
unexpected changes during shipment $[4,5]$, all of which translates into safer and more secure transport. Some authors have also suggested that most ICT solutions provide a general solution that does not satisfy the specific needs of the companies [6]. The number of software companies offering modularised software solutions that better fit the individual needs of logistics and supply chain companies has increased in recent years in an attempt to solve this. Voordijk et al. (2006) also noted the advantages of modularity, and state that "modularity provides the kind of flexibility that enables firms to serve a variety of customer needs" [7]. The development of software solutions with a multi-module structure that better fit the needs of different customers would therefore increase their market acceptance. In recent years many authors have defined a series of methods for the development of modular platforms [8]. Modularity has three main advantages: it makes complexity manageable, enables the development of work in parallel (reducing development time), and is more flexible, since it allows an easier implementation of potential future needs [9].

The acceptance of recent ICT advances for freight transport in Europe is very slow [10]. The low uptake of ICT solutions highlights the importance of analysing barriers in the design stage for smooth future implementation. All these issues, together with the approach followed in this study, can be seen in Fig. 1. In this paper we introduce a new methodology called the 'implementation acceleration methodology for ICT (IAM-ICT)', which looks for a greater implementation of ICT in all sectors by analysing barriers at the design stage, not only from a qualitative, but also from a quantitative point of view.

The main aim of this paper is to introduce a methodology to identify, and establish a hierarchy of potential barriers to implementing ICT solutions in the TDG, and to analyse how they can be overcome. This methodology has great potential since it can further be extended to

\section{Transport of Dangerous Goods characteristics:}

- Hazardous.

- Accidents have high consequences.

- $\quad$ Sensitive to be used in terrorist attacks.

- Inefficiencies in transport documentation and safety measures according with international transport codes (ADR, RID, IMDG, IATA) produces economic loses to companies and delays.

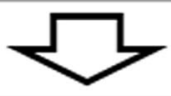

This can be solved using ICT solutions for a faster and more efficient management and transport.

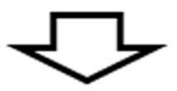

Low uptake of ICT solutions in transport and logistics

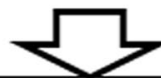

\section{Definition of the methodology for the analysis of barriers} (IAM-ICT)

1. Definition of barriers that hinder the use of ICT solutions for TDG (literature review + experts).

2. Hierarchy of barriers (AHP+Bayesian networks).

3. Overcome the most weighted barriers by co-creation.. 
other sectors that are having problems with the implementation of ICT technologies (e.g. logistics, health, etc.).

The paper's structure can be seen in Fig. 2. Structure of the methodology.

Section 2 is dedicated to a literature review, where the ICT barriers in the transport and logistics sector reported in previous bibliographies have been analysed. This information is used as the starting point in the design stage of an ICT solution and in the Step 2 of IAM-ICT methodology for the development of the first elicitation technique. Section 3 explains the methodology used, describing all the steps developed in the IAM-ICT methodology. This section is subdivided into subsections according to the different steps of the IAM-ICT methodology (see Fig. 2). Section 4 presents the results obtained, including, the prototype (describing the modules of the ICT solution used as case of study), AHP, Bayesian networks and co-creation in two types of companies or co-creation scenarios (one SME and one large company).
Finally, Section 5 concludes the paper, showing main findings, and suggests future research directions.

\section{Literature review and analysis of the state of the art}

In recent years, ICTs have played a very important role in the innovation of different sectors. There is a wide variety of ICT applications for the logistics and transport sector, including transportation management applications for management and planning, supply chain execution applications for a real-time sharing of information during the transport of the goods, field force automation to automate processes between the workforce and the different business processes, and fleet and freight management solutions used as reporting applications that give different transport data (e.g. travel times) to transport managers $[5,11]$. A recent study has demonstrated that the implementation of ICT has positive effects on supply chain agility and economic performance [12]. For example, the use of ICT technologies in the

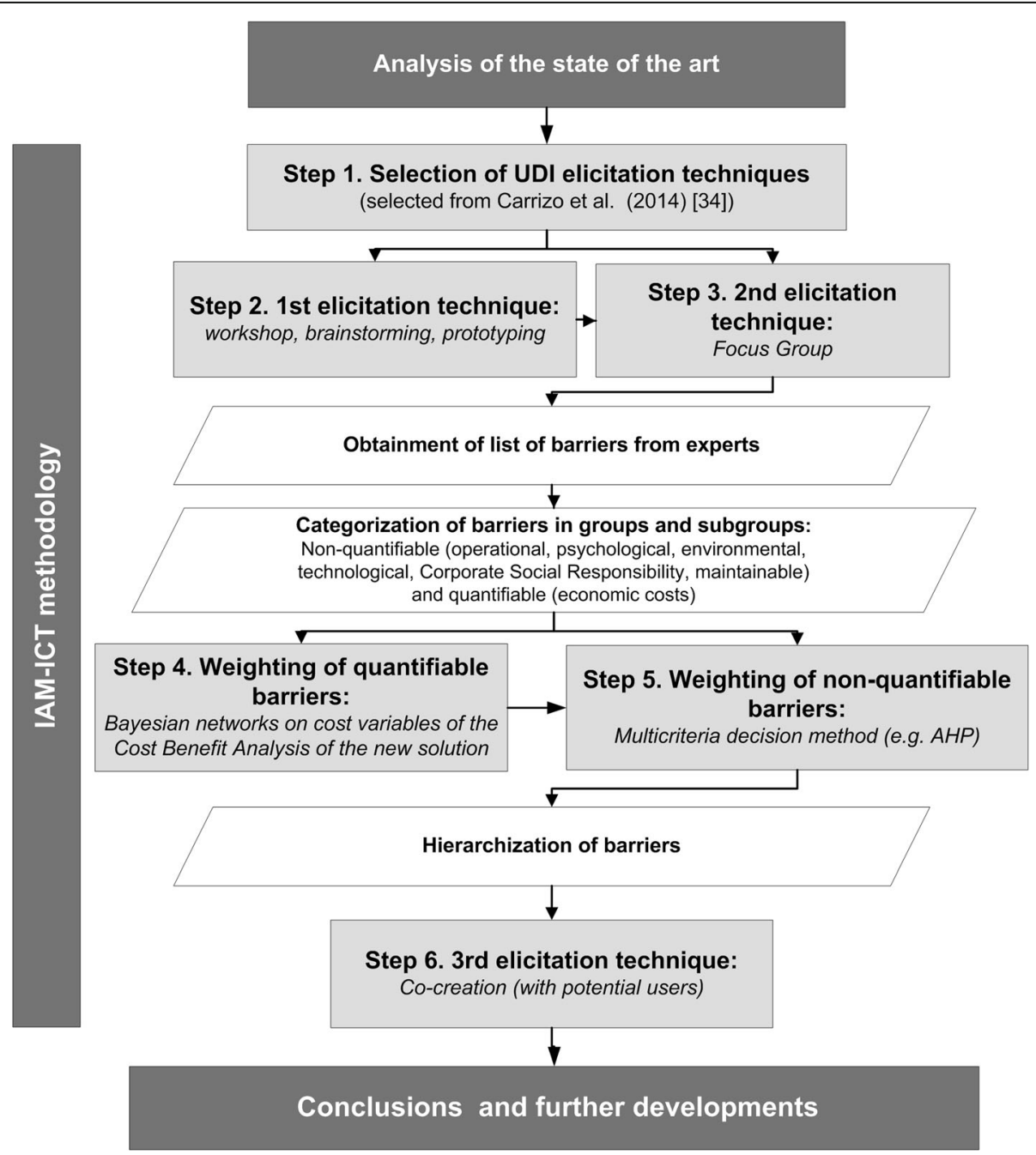

Fig. 2 Structure of the methodology 
transport sector has shown to have benefits for drivers, eliminating the time spent on administrative activities, which represents a $5.4 \%$ of the driver's working day [13].

Nowadays, some of the most prominent ICT technologies include big data, the internet of things (IoT), artificial intelligence and cloud computing [10]. Advances in digitalisation supported by these technologies are necessary to provide solutions for the management and safe transport of merchandise. This digitalisation process will avoid human errors and increase efficiency through a higher level of automatisation that will reduce expedition times and costs. The positive role of ICT in improving overall performance, customer service levels, visibility and communication between multimodal transport operators has been recognised by many stakeholders [6], however, there are many barriers that slow down the adoption of ICT solutions.

\subsection{Barriers to ICT adoption in the TDG supply chain}

There are many publications that analyse the factors affecting the adoption of ICT solutions, however, few studies have focused on the implementation of ICT in the transport and logistics sector. Pokharel (2005) identified four main factors that affect the level of ICT adoption by logistics companies, which include the logistic services provided, the size of the company, the number of industry or product types with which the company works, and the technological development and policy regarding ICT [6].

We have analysed the different barriers in three different groups: company-related barriers, external barriers and technical barriers.

Company-related barriers are those in which the behaviour of companies towards ICT adoption appears to be affected by the characteristics of the company itself, and include economic barriers, human capital restrictions and operation-related barriers.

Economic or financial barriers include the long implementation periods for ICT solutions [6] and the need for financial justification in order to fully implement an ICT solution [14], as well as insufficient compatibility between new ICT solutions and the existing solutions adopted by the company. This insufficient compatibility between solutions often leads to high substitution costs for firms, in order to intensify the use of the ICT [15]. ICT implementation can also be hampered by the cost of the investment needed to buy equipment (e.g. telematic equipment in the case of tracking and tracing applications), the installation and the integration of new ICT solutions with legacy systems [16, 17], and insufficient management support [18]. One of the main barriers to ICT adoption is uncertainty about timely returns on investment, and a lack of methods for the identification and analysis of potential benefits (in terms of costs and intangible benefits due to, for example, additional services) $[5,11,17]$.
Human capital restrictions also hinder the implementation of ICT. The lack of ICT specialists, together with insufficient training and the reluctance of personnel to change and to learn new technology are important aspects that affect the acceptance of ICT [15, 17]; as well as the attitude of managers and company policy about the implementation of new ICT solutions [5]. Harris et al. (2015) studied the barriers associated with the adoption of ICT in multimodal transport with a focus on operation-related barriers, including the lack of ICT specialists, the shortage of skills among personnel to operate new applications and insufficient ICT-oriented training - all barriers that may have a big impact on small companies due to the dearth of specialists [10]. Workers, such as drivers, also feel that the implementation of new technology would control them more strictly, feeling as if they were observed during the whole working day, and thus seeing new technological advances as an enemy rather than a tool that could facilitate their work [17]. They may even feel that their job is in danger if ICT solutions are implemented, leading to the sabotage of the process by the workers [19].

A deficient ICT strategy and insufficient knowledge of the potential gains to be made from ICT by managers [15], or a lack of management by company decision-makers, stand in the way of ICT implementation. Often the performance of an ICT technology or its future development is unknown or unclear, thereby restricting its adoption by companies $[15,19]$. There are also some psychological barriers when making a decision. Several studies show that the use of ICT is more positively perceived the bigger the company is $[6,20,21]$, possibly due to their higher financial stability which allows the planning of investments for long-term results (long-term vision), and where the objective is to increase their business volume. Patterson et al. (2003) suggest that "the more decentralized the organization, the more likely it will be to adopt supply chain technology" [21]. Pokharel (2005) considered whether the fact that a company dealt with many different types of products means that they would need a higher level of ICT implementation. The survey showed that this is not a factor that affects having a higher degree of ICT implementation, since companies handling large volumes of a specific product use higher levels of ICT; and therefore the implementation of ICT is not dependent on handling different types of products or not [6]. In a similar vein, Golob and Regan (2002) report that carriers that handle added value goods or which need a higher control (e.g. refrigerated substances, dangerous goods) are more keen on the adoption of ICT solutions for the tracking and tracing of goods [22]. Previous experiences with similar ICT solutions and a company's current technological development can affect the decision of whether or not to use a new ICT solution [5, 6, 15]. Patterson et al. (2003) 
indicated that organisations with low success in implementing ICT technologies in the past are more likely to adopt new technologies, since those who have already adopted old technologies would have to invest a huge quantity of money to make profit from them and so they are not made redundant if another new technology is used [21]. Those entities that have included a supply chain management strategy in their corporate strategy are also more likely to adopt new technologies to manage their supply chain [21].

External barriers are those in which the behaviour of companies towards the adoption of ICT appears to be affected by the behaviour of other players in the market. Partnership among companies in the supply chain, customer attitudes towards ICT or a reluctance to adopt technology may prevent companies from being involved in ICT projects [5], or favour their implementation if there is a good climate between supply chain members [21]. The adoption of ICTs that involve different members of the supply chain therefore needs them all to have a similar ICT strategy in order to accomplish a high implementability of the solution [23]. In the review recently developed by Gunasekaran et al. (2017), they conclude that organisations should think strategically about which technology could give them competitive advantage and how to integrate it with other supply chain members (alignment), and should include fast adaptation to new scenarios in their business strategy (adaptability and agility). If these three concepts are not considered the new ICT solution will eventually fail [24].

A study by Jacobsson et al. (2017) showed that deficiencies in the information exchange between involved actors are common and can be a barrier to the implementation of an ICT solution for the multimodal TDG [25]. Marchet et al. (2009) analysed ICT adoption in the Italian freight transportation industry, and said that one of the main reasons for the low level of ICT implementation is the fragmentation of the Italian logistics and transportation industry due to the multiple levels of sub-contracting [11]. Integration between the different ICT solutions and technologies used by the different members of the supply chain is then also required for the efficient implementation of new ICT solutions $[5,26]$.

On the other hand, customers can have a strong influence on their suppliers, pushing them to the implementation of specific ICT solutions that can improve their communication or can distinguish them from others [21, 27]. Patterson (2003) also identified environmental uncertainty as a factor affecting the adoption of ICT technologies, understanding uncertainty as unpredictable changes from suppliers or from customers, changes in the production processes or any fast change that cannot be predicted beforehand. Those companies that have more environmental uncertainty are then more keen on the implementation of technologies for greater control over their business [21].

Technical-related barriers are the third type of barriers, and these include the interoperability of systems, ICT integration, standardisation, security and data protection. These kinds of barriers relate to the technological constraints that hamper operators from making full use of ICT solutions [4, 10]. Pokharel (2005) analysed ICT adoption by transport and logistics companies through the development of a survey to 600 companies, of which 84 responded and only 45 were valid [6]. From a technical point of view, the analysis of the responses showed that ICT adoption could be facilitated by a good infrastructure, the availability of technology to meet the needs of the industry and how industry managers are motivated economically: if there is a good opportunity to increase profits. He also identifies the costs, the management support and the rapid obsolescence of technology as some of the main barriers. Stakeholders feel that ICT solutions will soon be updated, mainly due to the fast evolution of technology and the use of tailored solutions for each company [6]. Helo and Szekely (2005) developed a review of the different software applications, analysed their benefits, and indicated the importance of the integration between different software solutions and the creation of standards [26]. This low level of integration between the different ICT solutions was also identified by other authors $[11,17]$.

\subsection{Methodologies used for the development and analysis of ICT solutions}

A variety of methods can be found in the literature for i) the development of new ICT solutions, and ii) for the analysis of the benefits and barriers of developed ICT solutions.

Software usually follows a series of development phases. Two of the most common methodologies are the ESA standard [28] and the Agile methodology [29]. Droschl et al. (2002) compared the development of a software module using the ESA standard with the formal Vienna development method (VDM) and found that the use of VDM led to the fulfillment of more requirements, thus increasing the quality of the developed product [30]. Many other methods for the design, development and validation of a software module or a software solution can be found in the bibliography (e.g. fuzzy clustering, voice of the customer (VOC), the design structure matrix (DSM), modular function deployment (MFD)) [8], however, many of these methods are centred on user requirements, the design of the architecture, the development and the validation, and do not include a specific analysis identifying the barriers to implementation that the developed solution will have to face, and how they should be handled in the design phase so that they can be overcome. A comparison 
of the characteristics of current methodologies and the methodology proposed within this paper, as well as their impact on the effectiveness of ICT implementation can be found in Table 1.

The most common methods for the analysis of ICT deployment barriers in companies are literature reviews and surveys [5, 6, 17, 21]. Sternberg et al. (2014) used direct observation for the analysis of road haulage operations and how ICT technologies could benefit truck drivers [13]. Tseng et al. (2011) used the Fuzzy DEMATEL method to show interrelationships between criteria [31]. Kengpol and Tuominen (2006) proposed a methodology to help decision makers in the evaluation of information technology proposals, including a qualitative and a quantitative analysis; the methods used were the analytic network process (ANP), Delphi, and Maximise Agreement Heuristic (MAH) [32]. Marchet et al. (2009) evaluated ICT adoption using multiple-case studies based on interviews. This is a qualitative method with three steps: literature review, interviews and case studies [11]. Zeimpekis and Giaglis (2006) also analysed the circumstances of the success of telematic solutions implemented in SMEs using a three-phase research methodology which included a literature review, a qualitative method (interviews) and a quantitative method (online questionnaire) [17]. Patterson et al. (2003) developed a model of the antecedents of supply chain technology adoption in which seven different hypothesis were analysed and validated through a survey which uses the Likert scale [21].

Other methods that have been used for the analysis of barriers in other fields include interpretive structural modeling (ISM) a methodology for the analysis of dependencies between barriers, and the Impact Matrix Cross-Reference Multiplication Applied to a Classification (MICMAC) method for the classification and quantification of the barriers [19]; as well methods already mentioned, such as literature reviews, Delphi and AHP [33].

The design and analysis of the barriers to and benefits of ICT are usually analysed separately. Studies found during the literature review show that barriers to ICT adoption have only been analysed after the development of the ICT solution. On the other hand, ICT design methodologies are focused on the gathering of user requirements, the definition of the system architecture and on development and validation tasks, but they do not include an analysis of potential barriers once the product comes onto the market. There is therefore a gap in the development of studies for the ex-ante identification of barriers to new ICT solutions, and their inclusion in ICT design and development methodologies. The main contribution of this

Table 1 Comparison of current methodologies and IAM-ICT methodology, and impact on its effectiveness in the implementation of innovative ICTs

\begin{tabular}{|c|c|c|c|}
\hline Name & Characteristics & Ref & Advantages/Effectiveness of IAM-ICT methodology \\
\hline ESA standard & $\begin{array}{l}\text { - General methodology that includes practices and } \\
\text { guidelines for the phases of software development } \\
\text { including transfer, operations and maintenance and } \\
\text { prototyping concept. }\end{array}$ & {$[28]$} & $\begin{array}{l}\text { - IAM-ICT specifies the tools to be used in each of these } \\
\text { development phases except for transfer, operations and } \\
\text { maintenance phases. } \\
\text { - It includes the prioritisation of the acceptance barriers. } \\
\text { Co-creation is used to resolve implementation barriers. }\end{array}$ \\
\hline Agile methodology & $\begin{array}{l}\text { - Flexible method allowing frequent and regular } \\
\text { software releases. } \\
\text { - Includes agile methods giving general ideas of } \\
\text { what to be done. }\end{array}$ & {$[29]$} & $\begin{array}{l}\text { - IAM-ICT defines the methods to be used in the } \\
\text { requirements gathering phase. } \\
\text { Prioritisation of barriers in the design phase. } \\
\text { - Co-creation is used to resolve implementation barriers. }\end{array}$ \\
\hline $\begin{array}{l}\text { Vienna development } \\
\text { method (VDM) }\end{array}$ & $\begin{array}{l}\text { - Used for the detection of errors and improvement } \\
\text { of requirements. Allows the analysis of designs and } \\
\text { identification of defects at an early stage of system } \\
\text { development. }\end{array}$ & {$[30]$} & $\begin{array}{l}\text { - IAM-ICT addresses market needs within a specific scope } \\
\text { and prioritises barriers in the design phase. } \\
\text { - Co-creation is used to resolve implementation barriers. }\end{array}$ \\
\hline Fuzzy clustering & $\begin{array}{l}\text { - Method to hierarchize a set of objects and } \\
\text { identify modules. }\end{array}$ & {$[8]$} & $\begin{array}{l}\text { - IAM-ICT includes the prioritisation of the acceptance barriers } \\
\text { and how they can be overcome using co-creation methods. }\end{array}$ \\
\hline $\begin{array}{l}\text { Voice of the } \\
\text { customer (VOC) }\end{array}$ & $\begin{array}{l}\text { - Method to gather customer needs as to how } \\
\text { they use the product, through interviews, } \\
\text { surveys, etc. }\end{array}$ & {$[8]$} & $\begin{array}{l}\text { - IAM-ICT includes: the selection of the most appropriate } \\
\text { elicitation technique, the consideration of cost benefit } \\
\text { analysis, prototyping, and the prioritisation of } \\
\text { implementation barriers. }\end{array}$ \\
\hline $\begin{array}{l}\text { Design structure } \\
\text { matrix (DSM) }\end{array}$ & $\begin{array}{l}\text { - Used to represent activity dependencies. } \\
\text { - Allows the formation of clusters that indicate } \\
\text { possible modules. }\end{array}$ & {$[8]$} & $\begin{array}{l}\text { - IAM-ICT includes the design of the modules and the } \\
\text { development of a prototype, the selection of the most } \\
\text { appropriate elicitation technique, UDI techniques to } \\
\text { gather requirements and implementation barriers, } \\
\text { the consideration of cost benefit analysis, and the } \\
\text { prioritisation of implementation barriers. }\end{array}$ \\
\hline $\begin{array}{l}\text { Modular function } \\
\text { deployment (MFD) }\end{array}$ & $\begin{array}{l}\text { - Manages data efficiently and performs } \\
\text { numerical or statistical analyses (with qualitative } \\
\text { and quantitative data). } \\
\text { - Allows the formation and definition of clusters. }\end{array}$ & {$[8]$} & $\begin{array}{l}\text { - IAM-ICT methodology includes an additional phase } \\
\text { for the analysis and prioritisation of implementation } \\
\text { barriers; using co-creation to resolve them. }\end{array}$ \\
\hline
\end{tabular}


paper is the development of a methodology that encompasses both the design of the software solution through the different elicitation techniques previously used in the literature, and the analysis of qualitative and quantitative barriers through multicriteria decision methods, Bayesian networks and co-creation.

\section{IAM-ICT methodology: definition of stages}

The literature review introduced a list of barriers that can affect whether decision-makers implement a new ICT solution for multimodal transport. In this paper we will specify what the barriers are in the case of ICT solutions in the multimodal TDG. In order to do so, a methodology has been developed - the implementation accelerator methodology for ICT (IAM-ICT) - for the identification, weighting, prioritisation and overcoming of these barriers or key factors, by using a multi-modular ICT solution for the TDG as a case study (see Fig. 3).

The IAM-ICT methodology can be divided into six main steps (see Fig. 2), which are detailed in the following subsections (from 3.1, 3.2, 3.3, 3.4, 3.5 and 3.6):

- Step 1: the selection of the most appropriate elicitation or UDI techniques according with Carrizo et al. [34].

- Step 2: the development of a first round of UDI techniques (workshop, brainstorming, prototyping and cost benefit analysis (CBA) of the developed prototype) in order to help in the first design of the ICT solution and to obtain initial potential barriers.

- Step 3: the development of a second elicitation technique (i.e. focus group) to obtain information from stakeholders, based on the first design of the solution for the improvement of the initial prototype and the identification of other barriers additional to those identified in Step 2, as well as of the parameters affecting the calculation of the solution's CBA.

- Step 4: the weighting of quantitative (economic) barriers through: first, obtaining data regarding the CBA from companies; and finally, prioritisation using Bayesian networks.

- Step 5: those variables that are qualitative were weighted using the AHP. This finally led to the prioritisation of the barriers.

- Step 6: the last step of IAM-ICT focuses on the analysis in situ, of the customer facilities, through a cocreation session analysing how to solve those barriers that have obtained a higher weight, and which, then, have a greater effect in hindering the implementation of the analysed ICT solution.

\subsection{Selection of UDI elicitation techniques}

The study carried out by Carrizo et al. (2014) was used in order to select the most appropriate elicitation

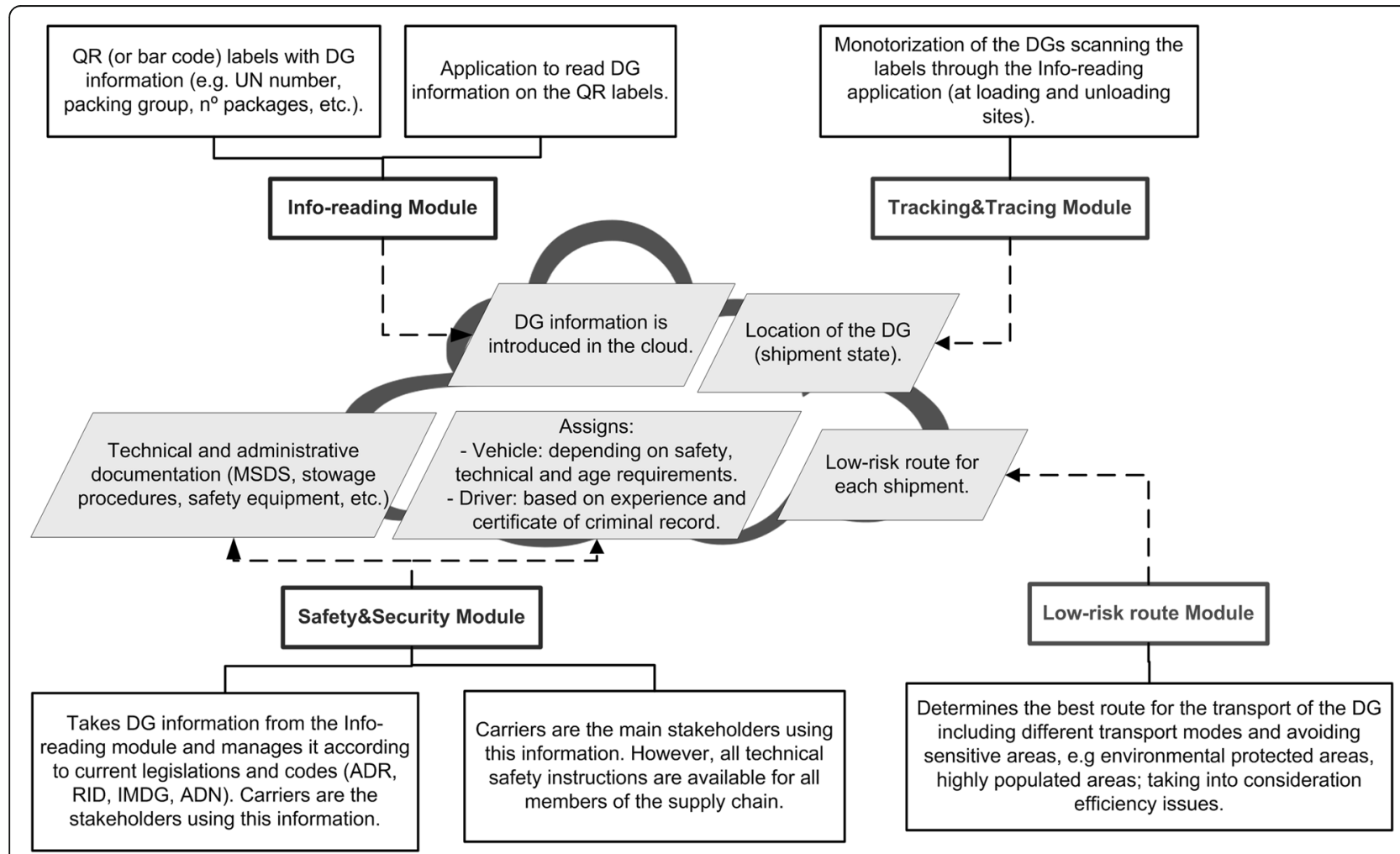

Fig. 3 Prototype scheme of the new cloud computing solution for the transport of dangerous goods 
techniques to obtain the requirements at each development stage, which develops a procedure that establishes which techniques are more appropriate depending on the type of problem, and the skills of the elicitor and the informants, while also taking into account temporal aspects (e.g. the availability of informants) [34]. This method deals with the selection of a requirements elicitation technique for software product requirements, offering a wide range of possible techniques to capture more information about requirements. Table 2 shows the elicitation techniques selected for each step, from lower to higher knowledge on the subject.

\subsection{Workshop, brainstorming and prototyping}

An initial workshop was carried out with different members of the supply chain in order to obtain a first and global vision of the problem. During the session, the new ICT tool (used as a living lab) for the TDG was introduced and future advances/requirements were analysed. At the end of the session, the participants completed independent questionnaires with a view to gathering their individual opinions. After this initial vision, the second technique was a LEGO serious play session, used as a brainstorming and role-playing technique [35]. This type of session was used as a first approach to defining an initial prototype of an ICT for the TDG and to identify barriers that will need to be faced in order to implement the ICT solution. With all this information, an initial prototype identifying the four modules of the new software solution was developed (see Fig. 3).

\subsection{Focus group}

The focus group was formed to represent all the stakeholders involved in the TDG supply chain. It comprised the technical manager of a petroleum company, the project manager of a chemical manufacturing company, the general manager of a road transport company, an informatics technician and a commercial manager in a technology services company specialising in the logistics and port sector, a member of a railway company, and a member of a forwarder involved in the maritime and air transport of goods.

Barriers to the initial prototype were studied in order to prepare the focus group session. These barriers can be classified as not quantifiable (operational, psychological, etc.) and quantifiable barriers; the latter can be understood as economic barriers and can be analysed using an economic cost analysis. A CBA was carried out in accordance with the ASSIST (assisted e-service deployment) methodology [36]. The (i) initial prototype, (ii) initially detected barriers to the prototype and (iii) CBA were therefore introduced to the attendees of the focus group so they could analyse them, change, add or remove any issue discussed during the session, and improve the quality and implementation of the new ICT solution for the TDG.

\subsection{Bayesian networks (BNs) - quantifiable barriers}

One of the results of the focus group was identifying quantifiable or economic barriers. The weighting of the quantifiable barriers was carried out using BNs on the cost variables of the CBA. The value of the costs variables were obtained from six companies. Data was obtained for each variable for each quarter from 2012 to 2016. The main objective of BNs is to compute the distribution probabilities in a set of variables $\left(x_{i}\right)$ according to the experimental data of the variables $\left(v_{i k}\right)$ identifying the belief network structure $\mathrm{B}_{\mathrm{S}}$ with a maximum likelihood (ML).

Let $\mathrm{D}$ be the database of $\mathrm{n}$ discrete variables $x_{i}$ with $r_{i}$ possible value assignments: $v_{i k}\left(1 \leq k \leq r_{i}\right)$. The likelihood $(\mathrm{L})$ of $\mathrm{D}$ and a given belief network structure $\mathrm{B}_{\mathrm{S}}$ is:

$$
L=P\left(B_{S}, D\right)=\int_{B_{P}} P\left(D \mid B_{S}\right) \cdot f\left(B_{P} \mid B_{S}\right) \cdot P\left(B_{S}\right) \cdot d B_{P}
$$

where $B_{P}$ is a vector whose values denote the conditional probability assignments associated with the belief network structure $\mathrm{B}_{\mathrm{S}}$ and $f$ is the conditional probability density function over $B_{P}$ given $B_{S}$. Therefore, assuming equal priors on $\mathrm{B}_{\mathrm{S}}$ and $f\left(B_{P} \mid B_{S}\right)$ as a second-order probability uniformly distributed, Eq. 1 can be formulated as:

$$
L=P\left(B_{S}, D\right)=P\left(B_{S}\right) \cdot \prod_{i=1}^{n} \prod_{j=1}^{q_{i}} \frac{\left(r_{i}-1\right) !}{\left(N_{i j}+r_{i}-1\right) !} \cdot \prod_{k=1}^{r_{i}} N_{i j k} !
$$

where $\mathrm{N}_{\mathrm{ij}}$ is the number of cases in which $\mathrm{Pa}_{\mathrm{i}}$ (parents of $x_{i}$ in $B_{S}$ ) has the $\mathrm{j}$-th configuration, $\mathrm{N}_{\mathrm{ijk}}$ is the number of cases in which variable $x_{i}$ has the value $v_{i k}$ when $\mathrm{Pa}_{\mathrm{i}}$ has their $j$-th configuration and $q_{i}$ is the number of possible configurations of $\mathrm{Pa}_{\mathrm{i}}$.

We used a heuristic-search method to maximise $\mathrm{L}$ achieving ML, based on the algorithm $\mathrm{K} 2$ that begins by making the assumption that a node $\mathrm{x}_{\mathrm{i}}$ has no parents

Table 2 UDI elicitation techniques selected from Carrizo et al. [34]

\begin{tabular}{ll}
\hline Steps (in order) & Results \\
\hline Workshop (questionnaire), brainstorming (role playing) and prototyping. & $\begin{array}{l}\text { Initial prototype - quantifiable and not quantifiable barriers - } \\
\text { cost-benefit analysis (CBA). }\end{array}$ \\
Focus group. & $\begin{array}{l}\text { Validation of: prototype - barriers - CBA. } \\
\text { Co-creation/use cases. }\end{array}$ \\
\hline
\end{tabular}


$\mathrm{Pa}_{\mathrm{i}}$, and then adds incrementally that parent whose addition increases $P\left(B_{S}, D\right)$. When the addition of no single parent can increase the probability, we stop adding parents to the node [37]. The $B_{S}$ with a ML is obtained when $B_{S}$ is the structure with the ML after evaluating it forward and backwards (from parents to children, and inversely), and when removing data randomly from $80 \%$ to $50 \%$, variables at the first level of the network do not change.

\subsection{Analytic hierarchy process (AHP) - not quantifiable barriers}

One of the results of the focus group was obtaining a list of barriers (quantifiable and not quantifiable) to the new ICT solution for TDG, however, not all the barriers have the same importance or affect in the eyes of the decision-makers [38]. The priorities or importance of qualitative barriers were obtained using the AHP method.

Questionnaires aimed at gathering the opinions of the experts were prepared using the following steps:

i. An expert panel was created according to the stakeholder theory recommendations to avoid conflicts of interest $[39,40]$. The expert panel was formed of seven members of the companies involved in the focus group, but different to the attendees of the focus group session.

ii. The barriers were classified into groups (first level) and subgroups (second and third levels) to enable comparison between barriers with similar characteristics at the same level by the experts (see Fig. 4).

iii. The opinions were made available by means of questionnaires filled in independently by the experts. The collected opinions constitute matrices of comparison using the scale of Saaty [41]. Seven experts carried out the pairwise comparison process. The Delphi method was used to reach consensus between expert responses [42]. The data obtained in each Delphi round was analysed using a binomial statistical test to determine an appropriate consensus level. The null hypothesis of the statistical test was:

$\mathrm{H}_{0}=$ The median med is the consensus preference between all experts.

\section{A binomial table distribution was used, where:}

- Success is considered when the expert provides med as a preference.

- Failure is considered when the expert does not provide med as a preference.

We should accept the null hypothesis if at least three of the seven experts match their preferences with the median according to the binomial distribution $\mathrm{B}(P=0.11, N=7)$, where $\mathrm{P}$, considering Saaty's scale, is the probability that an expert provides med as a preference $(\mathrm{P}=0.11)$ and 7 is the number of experts, or independent opinions. This probability distribution shows that the probability of obtaining by chance three or more successes is 0.034 . Therefore, it is appropriate to consider three successes as consensus with a $p$-value lower than 0.05 .

The calculation of the global normalised weights ( $W_{C G}$ ) of each barrier was obtained following the AHP methodology [41, 43-45], with a modification, the local normalised weights of economic costs second level barriers (C71- C75) were obtained using Bayesian networks due to their quantitative character.

\subsection{Co-creation}

Since the size of the company has a direct effect on the solution developed $[6,15,20]$, for the co-creation sessions, the new ICT solution for the TDG was analysed in two co-designed schemes, in an SME and in a large company. The ICT solution was used as a living lab in both case studies in order to analyse how the identified barriers can be overcome.

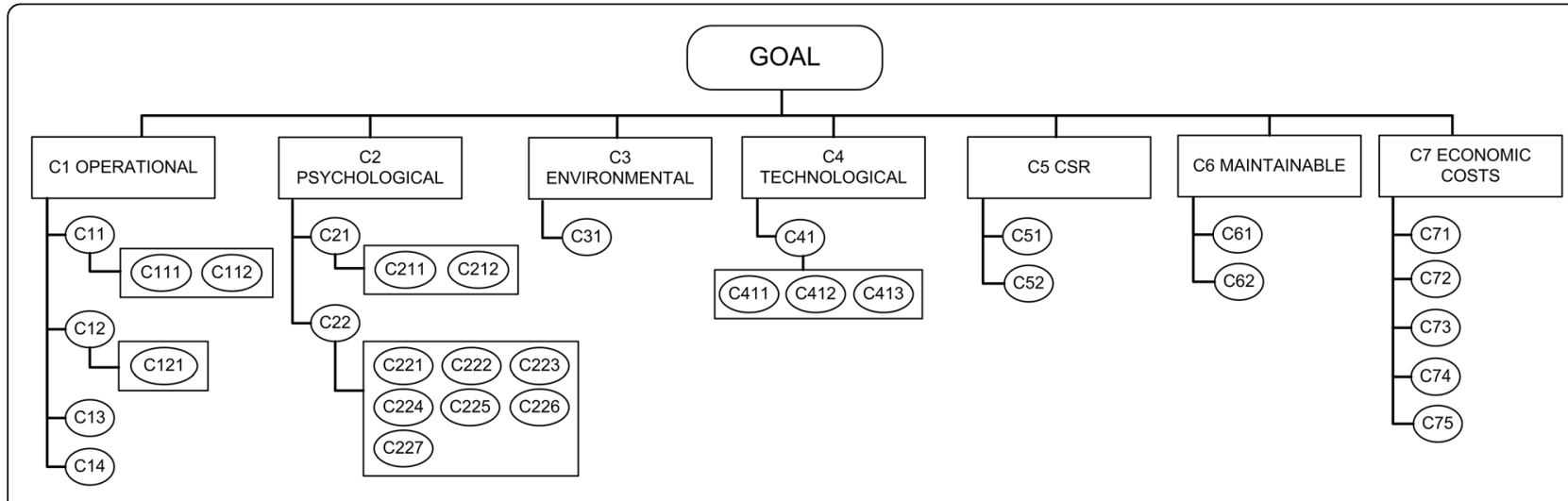

Fig. 4 Hierarchical model of barriers for the prototype presented in Fig. 3 


\section{An empirical case study}

The IAM-ICT was applied in a living lab ICT solution for the TDG. The new ICT solution is a multi-modular ICT global solution for the TDG that will solve the management of all the technical requirements related to the TDG according to the ADR, RID, ADN and IMDG international codes for road, rail, inland waterway and maritime transport, respectively; as well as the assignment of the most appropriate vehicle and driver for each shipment (Safety \& Security module); it will also provide safe and secure routes (low-risk routes) with real-time tracking and monitoring (tracking and tracing, T\&T) of the dangerous goods. The developed prototype, defined after Step 2 of the methodology (workshop, brainstorming and prototyping), can be seen in Fig. 3.

The design phase of the new ICT tool for the TDG led to the development of four modules: "Safety \& Security", "Info-Reading", "Low-Risk Route" and "Tracking \& Tracing". The "Info-Reading" module allows the introduction of the information of the goods to be transported in the cloud. QR labels are generated with the shipping information (i.e. UN number, origin, destination, shipping name, packing group, environmental dangerousness, weight, height and filling degree for tanks/tank containers). Scanning the labels introduces the information to the system, information that will be used by the other three modules. The "Safety E Security" module allows the digital and shared management of information between all members of the supply chain. The "Info-Reading" module introduces the type of product/s, the quantity, the packing group and the origin and destination of each of the shipments, and "Safety E Security" module generates all the technical, safety and administrative documentation (e.g. MSDS, stowage procedure, safety equipment, transport document for hazardous goods, check list, special provisions) according to the transport codes. This information is uploaded to the Cloud, and sent to those members of the supply chain that will need it. Optionally, this module also allows the introduction of vehicle and driver information for the automatic assignment of the shipment: for example, high consequence dangerous goods would be assigned to the most experienced drivers, drivers free of criminal records, and to the appropriate trucks. The "Low-Risk Route" module uses this information for the calculation of the best route, based not only on costs and time, but also taking into account environmental, safety and security criteria (e.g. avoiding environmental protected areas, highly populated zones). The aim of the "Tracking and tracing" module is to monitor the position of the freight by scanning the QR label in the origin, destination and any intermediate point, and the uploading of the information to the Cloud where all the members of the supply chain can check the state of the shipment.

\section{Results and discussion: application of IAM-ICT methodology in a new ICT solution for the TDG}

After the development of the workshop, brainstorming session and focus group, a list of barriers to the prototype of the ICT solution for the TDG was obtained. These barriers were classified in clusters (see Fig. 4). The definition of each of the barriers within each cluster is described in Table 3.

Barriers were classified as seven first-level barriers, which will be compared using the AHP methodology. Second- and third-level barriers have also been detailed for these seven first-level criteria. All the sub-barriers will also be weighted using the AHP, with the exception of the quantitative sub-barriers (C71-C75) corresponding to the economic costs, which will be weighted using Bayesian networks.

\subsection{Bayesian networks (BNs) - quantifiable barriers}

The local normalised weight of quantifiable barriers $\left(w_{c j}\right)$ related to implementation and integration costs from the CBA are described in Table 4. The analysis of the state of the art, together with the applied UDI techniques showed that there are five main economic issues that can affect decision makers in the implementation or not of our ICT solution. These are:

1. License: cost associated with the investment in the annual licenses for the ICT solutions.

2. Training: investment in training the professionals that will use the ICT solutions.

3. ICT management: cost of the employees responsible of the ICT system.

4. Label processing: printing costs of the labels.

5. Cost of devices: costs of buying new devices to read the labels (e.g. smartphones, ATEX devices allowed in explosive atmospheres).

The costs of the quantifiable barriers $\left(c_{j}\right)$ (Table 4 ) could not be directly measured from the industry because the ICT solution is a prototype and it has not yet been implemented. To quantify these barriers we therefore developed a CBA, identified the different cost and benefit variables, and assigned them to the different economic barriers (see Table 6). Since it is a modular solution used by different members of the supply chain, some barriers can affect one type of user and not another (e.g. shippers and loading sites do not need to buy devices to scan the labels so they won't have any cost related to buying scanning devices), this was also taken into account in the quantification of the barrier (see Table 5 and Eq. 4).

Dependences between $c_{j}$ and other already known variables $x_{i}$ affecting costs in the CBA, where the described algorithm $\mathrm{K} 2$ in the $\mathrm{BN}$ methodology is applied, were 
Table 3 Description of first-level barriers (dark grey), second-level barriers (light grey) and third-level barriers (white) for the implementation of an ICT solution for the TDG

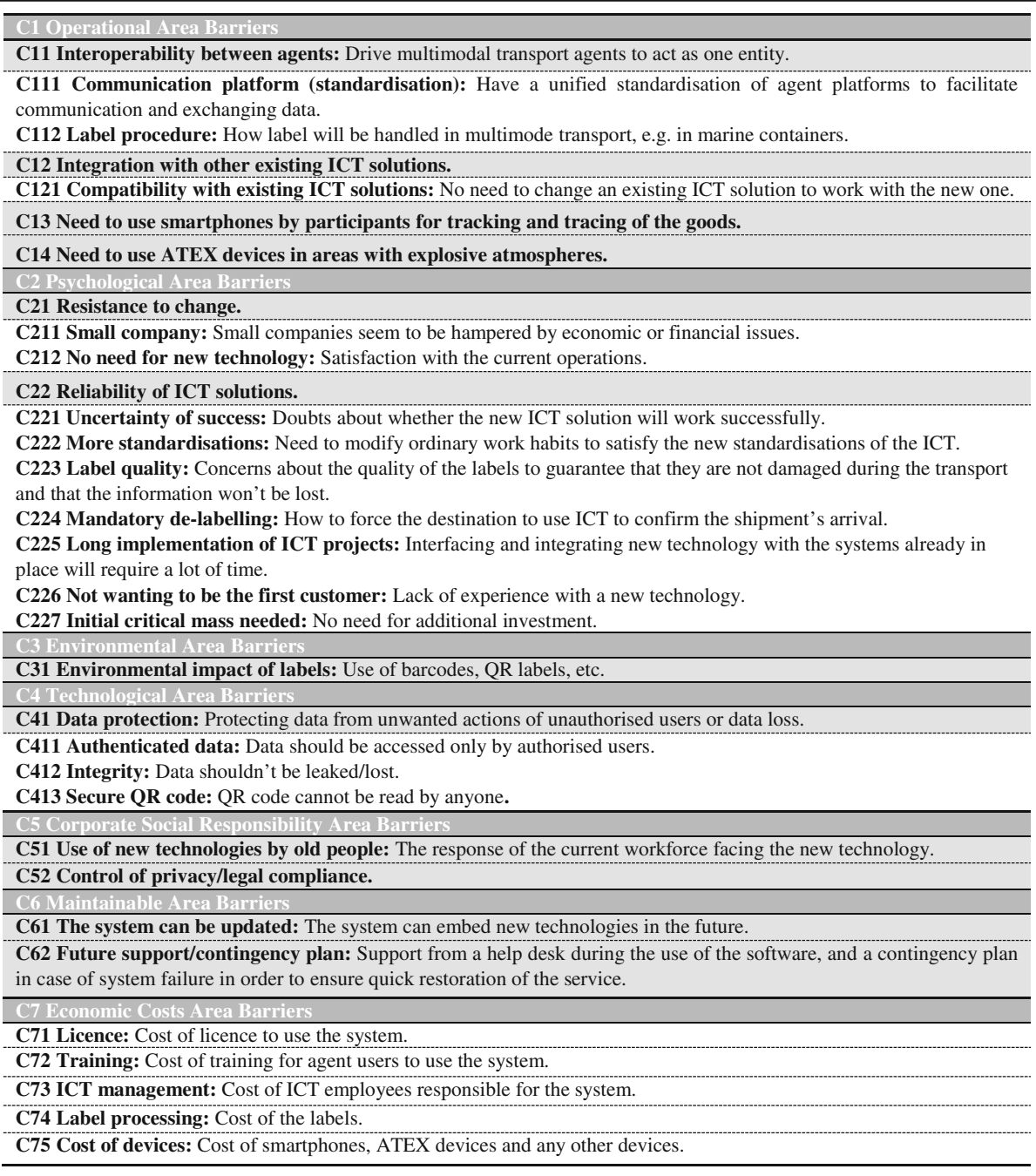

thus known. We assumed that total costs did not depend on other variables different from $x_{i}$. Table 6 shows those dependences and the weights obtained for variables $x_{i}$ by BN $\left(w_{x_{i}}\right)$. Database D and values $v_{i k}$ of $x_{i}$ were obtained from four SMEs and three large companies. Quantifiable barriers $c_{j}$ do not affect all agents participating in the supply chain (see Table 5).

Table 4 Local normalised weights of quantifiable barriers

\begin{tabular}{ll}
\hline Quantifiable barrier $\left(c_{j}\right)$ & $W_{C_{j}}$ \\
\hline C71 Licence & 0.1118 \\
C72 Training & 0.2861 \\
C73 ICT management & 0.2695 \\
C74 Label processing & 0.2215 \\
C75 Cost of devices & 0.1109 \\
\hline
\end{tabular}

The local normalised weights of quantifiable barriers $w_{c_{j}}$ shown in Table 4 were obtained through a mapping function $\mathrm{F}$ (see calculations in Additional file 2):

$$
\begin{aligned}
& F\left(x_{i}, w_{x_{i}}, z_{t}\right) \rightarrow w_{c_{j}} \\
& w_{c_{j}}=\frac{\sum_{t=1}^{4} \sum_{i=1}^{13} w_{x_{i}} \cdot K_{j_{i}} \cdot K_{j_{t}}}{\sum_{t=1}^{4} \sum_{j=1}^{5} \sum_{i=1}^{13} w_{x_{i}} \cdot K_{j_{i}} \cdot K_{j_{t}}}
\end{aligned}
$$

where $\Lambda_{\mathrm{j}_{\mathrm{i}}}$ and $K_{\mathrm{j}_{\mathrm{t}}}$ can be 0 or 1 if there is or is not a cross in rows $i$ and $t$ in Tables 6 and 5, respectively.

\subsection{Analytic hierarchy process (AHP) results}

The AHP method was used to weight qualitative barriers (see Additional file 1). In the first Delphi round, $48 \%$ of the fields in the AHP comparison matrices passed the statistical test. The other $52 \%$ reached consensus after a second round of Delphi. After obtaining the weights using 
Table 5 Quantifiable barriers affecting agents of the supply chain

\begin{tabular}{llllll}
\hline Agent of the supply chain $\left(z_{t}\right)$ & $\mathrm{C71}$ & $\mathrm{C72}$ & $\mathrm{C73}$ & $\mathrm{C74}$ & $\mathrm{C75}$ \\
\hline Shipper $\left(z_{1}\right)$ & $\times$ & $\times$ & $\times$ & & \\
Loading site $\left(z_{2}\right)$ & $\times$ & $\times$ & $\times$ & $\times$ & \\
Carrier $\left(z_{3}\right)$ & $\times$ & & $\times$ & $\times$ & $\times$ \\
Unloading site $\left(z_{4}\right)$ & $\times$ & $\times$ & $\times$ & $\times$ & $\times$ \\
\hline
\end{tabular}

the AHP method, the Pareto principle (80/20 rule) [46, 47] was applied to select the barriers with higher priority and those that need to be solved to obtain an ICT solution for the multimodal TDG with good market perspectives, that is, barriers with a cumulative weight up to 0.80 (see Table 7) will be studied during the two co-creation sessions.

\subsection{Co-creation}

The next step after defining and prioritising the major obstacles or barriers is co-creation or co-design, where stakeholders will be involved to find the appropriate solutions to these barriers. We use co-design to refer to the creativity of designers and people not trained in design working together in the design development process. These sessions were conducted in the stakeholders' companies, analysing the new practical solution regarding the identified barriers. The results of the two co-design sessions or case studies (one SME and one large company) regarding the developed solution for the multimodal TDG can be seen in Fig. 5 .

The main barriers for SMEs involved in the TDG, were: i) a lack of authority for making other members of their supply chain use the system (C211), thus hindering the potential of the application for the sharing of information between stakeholders, and ii) their high dependence on the transport agency management system (related to C111, C112 and C121). Previous studies have shown the relevance of company size and their relationship with other members of the supply chain in the implementation of ICT solutions. Pokharel (2005) suggested that ICT is perceived more positively with an increase in size of a company [6]. Perego et al. (2011) recognised via their literature review that one of the main external barriers to ICT adoption is the effect of other companies in the supply chain [5]. Chapman et al. (2002) noted that the adoption of ICTs by logistics companies means that all the members of the supply chain need a similar ICT strategy [23]. Patterson et al. (2003) developed a model of the variables affecting supply chain technology adoption based on an initial literature review, and used a survey to test the model. The developed model included organisational size and interorganisational factors, such as transaction climate and supply chain member pressure, as variables affecting technology implementation. Their study also noted the pressure that large companies apply to suppliers regarding the adoption of technologies [21].

The implementation of the use of QR labels (related to C112, C111 and C74) for the info-reading and tracking and tracing module will also face different barriers based on how it is managed in its supply chain. Small and medium companies depend on the systems of their transport companies, and then the implementation of the QR label system depends on the level of ICT implementation in these companies (related to C121 and C227). If they already use an advanced ICT solution for the tracking of the merchandise, the co-creation session showed that the most appropriate approach to facilitate the implementation of the developed solution is that they should incorporate additional information about dangerous goods (e.g. UN number, packing group, etc.),

Table 6 Dependences between quantifiable barriers $c_{j}$ and variables $x_{i}$ and weights of $x_{i}$ by BN

\begin{tabular}{|c|c|c|c|c|c|c|}
\hline Variable $\left(x_{i}\right)$ & $w_{x_{i}}$ & $\mathrm{C} 71$ & $\mathrm{C} 72$ & $\mathrm{C} 73$ & $\mathrm{C} 74$ & $\mathrm{C} 75$ \\
\hline Number of accidents $\left(x_{1}\right)$ & 0.1486 & & & & & \\
\hline Cost of human resources involved in dangerous goods $\left(x_{2}\right)$ & 0.1486 & & $x$ & & $x$ & \\
\hline Number of people working on a DG expedition $\left(x_{3}\right)$ & 0.1294 & $x$ & $x$ & $x$ & & $x$ \\
\hline Number of incidents $\left(x_{4}\right)$ & 0.1104 & & & & & \\
\hline Cost of informatics people $\left(x_{5}\right)$ & 0.0912 & & & $x$ & & \\
\hline Number of DG expeditions $\left(x_{6}\right)$ & 0.0912 & & & $x$ & $x$ & \\
\hline Number of steps in an expedition $\left(x_{7}\right)$ & 0.0722 & & & & & \\
\hline Number of DG packages per shipment $\left(x_{8}\right)$ & 0.0530 & & & & $x$ & \\
\hline Number of vehicles $\left(x_{9}\right)$ & 0.0530 & & & & & $x$ \\
\hline Number of hours of training in dangerous goods/safety $\left(x_{10}\right)$ & 0.0530 & & $x$ & & & \\
\hline Number of customs at frontiers per dangerous goods expedition $\left(x_{11}\right)$ & 0.0338 & & & & & \\
\hline Time for the preparation of an expedition $\left(x_{12}\right)$ & 0.0148 & & & & & \\
\hline Fees $\left(x_{13}\right)$ & 0 & & & & & \\
\hline
\end{tabular}


Table 7 Prioritised barriers, in descending order of preference, with their global normalised weight

\begin{tabular}{llllll}
\hline Barrier & $W_{C G}$ & Cumulative weight & Barrier & $W_{C G}$ & Cumulative weight \\
\hline C111 & 0.1336 & 0.13 & $C 51$ & 0.0150 & 0.90 \\
C112 & 0.1336 & 0.27 & C52 & 0.0150 & 0.92 \\
C121 & 0.1017 & 0.37 & C222 & 0.0131 & 0.93 \\
C411 & 0.0931 & 0.46 & C71 & 0.0120 & 0.94 \\
C61 & 0.0770 & 0.54 & C75 & 0.0119 & 0.95 \\
C14 & 0.0768 & 0.62 & C212 & 0.0110 & 0.96 \\
C211 & 0.0664 & 0.68 & $C 225$ & 0.0105 & 0.98 \\
C412 & 0.0425 & 0.73 & $C 413$ & 0.0097 & 0.98 \\
C31 & 0.0403 & 0.77 & C226 & 0.0064 & 0.99 \\
C72 & 0.0307 & 0.80 & C227 & 0.0043 & 1.00 \\
C73 & 0.0289 & 0.83 & $C 223$ & 0.0016 & 1.00 \\
C74 & 0.0238 & 0.85 & $C 221$ & 0.0015 & 1.00 \\
C13 & 0.0219 & 0.87 & $C 224$ & 0.0011 & 1.00 \\
C62 & 0.0154 & 0.89 & & & \\
\hline
\end{tabular}

in the labels currently used in the Transport Agency System (TAS), since current ICT solutions used by transport companies require the same data for the transport of dangerous goods and non-dangerous goods. TAS should also include a link to the cloud platform of the new ICT where the different stakeholders of a shipment can access all the documentation generated by the safety and security module, for the discrete tracking of the shipment. On the other hand, if the transport company is not using a tracking ICT solution, then the loading sites should implement the label system and lead the change in their supply chain. Previous studies have also noted as barriers the integration of ICT company strategies, and then of an initial critical mass with which to implement an ICT innovation (related to C227), and the investment costs needed and unclear return on investment of telematics services (related to C112). Studies such as that by Patterson et al. (2003) and Chapman et al. (2002) identified the need for integration between the ICT strategies of the different members of the supply chain in order to achieve the high implementability of a solution, corroborating the identified barrier C227 "Initial critical mass needed" [21, 23]. Zeimpekis and Giaglis (2006) showed that only $27 \%$ of SME logistics operators used telematic services, and that the main constraints are basically the unclear return on investment (ROI) and the investment cost of the telematic equipment [17].

In the case of large companies, the framework is different. Large companies have enough influence over their suppliers and customers that leading the implementation of a new management solution is not a problem for them. The main barrier for them is the integration of the new system with their ERP system (linked with identified barriers C121: compatibility with existing ICT solutions; and C111: communication platform). This finding has also been indicated in previous literature, which identified the compatibility between new and existing technologies within a company as one of the problems of ICT adoption; the higher the integration between different solutions the higher the acceptance of the new ICT solution [5, 11, 15, 17]. Marchet et al. (2009), using multiple-case studies, identified the need for a higher level of integration in order to realise all benefits derived from applications working together [11]. In line with this observation, Zeimpekis and Giaglis (2006) indicated the integration and interfacing of telematics with current supply chain systems (e.g. ERP, WMS) as a constraint [17]. To solve this integration problem and increase acceptance, the new solution should take all the information automatically from the ERP system used by the companies in order to avoid the duplication of tasks and agility, and then facilitate the use of the new ICTs by large companies. There are two potential scenarios in this co-creation scheme: i) the transport is contracted by the company that loads the freight; and ii) the transport is contracted by the

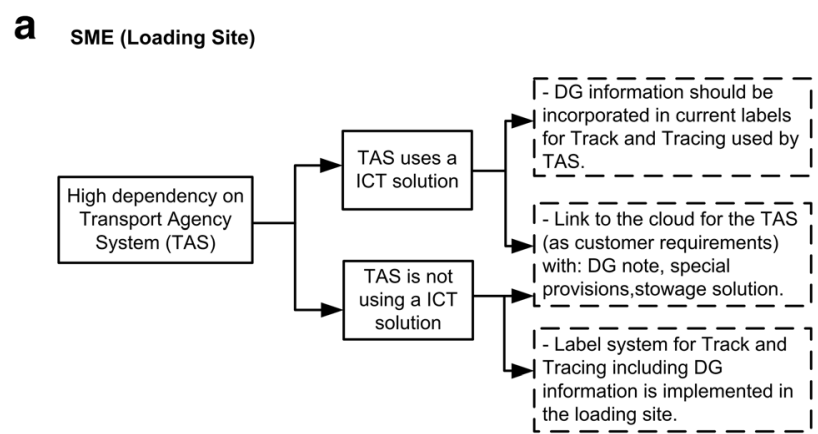

b

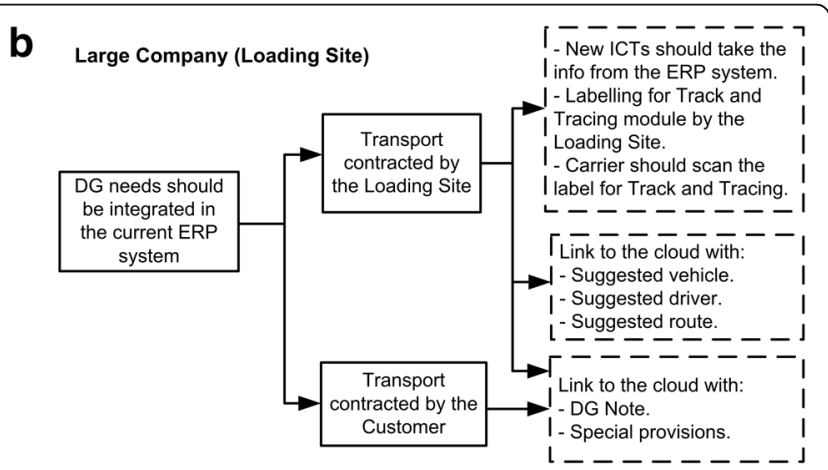

Fig. 5 Conclusions obtained during the two case studies. a) co-creation for an SME, and b) co-creation in a large chemical company 
customer. If the transport is contracted by the large company which does the loading of the freight, in addition to taking the information from the ERP system, the labelling system should also be implemented in the loading site and the drivers from the transport company should use the scanning application of the Track and Tracing module for the monitoring of the freight. Large chemical companies are very aware of the dangerous nature of hazardous goods and the need to have them controlled as much as they can. In order to have this control, those members of the supply chain not using the developed software solution would need access to some of the information generated by it. This information should therefore be available to them via a link to the Cloud sent to their e-mail which would give them information about the vehicle and driver suggested for a specific shipment, and the suggested low risk-route. In the second scenario, where the transport is contracted by the customer, then the system should send a link to the customer for the dangerous goods note and the special provisions needed for safe transport.

The literature includes some works in the area of ICT technologies for the supply chain, but most are focused on the definition of the ICT structure and functions, and the pre-assessment of barriers in the design stage for the new ICT solution is not addressed. For example, Kärkkäinen et al. (2004) described the benefits of a new tracking solution model compared with previous models [27] and analysed the difficulties of current tracking solutions in multi-company supply networks through a literature review, developing a new tracking solution and analysing its performance in a case study. The methodology addressed problems which were found in tracking solutions, but barriers to the future implementation of the new solution were not analysed, as is proposed in this paper.

\section{Conclusions and further developments}

The increasing presence of dangerous goods on our roads, together with their significant hazards, the strict regulations for their transport and handling, and the increasing number of terrorist attacks, highlights the importance of having greater control and less human intervention in this field. This objective can be achieved through the development of ICT solutions for a more automatised supply chain for the TDG. Many studies, however, report the low acceptance of current developed ICT solutions.

The analysis of the state of the art identified a gap in the methods for the ex-ante identification of barriers to new ICT solutions, and their consideration in the ICT design. On the one hand, the analysis of barriers to ICT implementation are focused only on ICT solutions already implemented in the market, and on the other hand, there is a wide variety of methods for the development of ICT solutions but none that include a pre-analysis of potential barriers to implementation once launched on the market.

In this paper, key factors for the implementation and integration of a new multi-modular ICT solution in SMEs and large companies involved in multimodal TDG have been analysed; and the design of a novel methodology to overcome these barriers at an early stage has been developed, the IAM-ICT methodology, which can be applied to other fields. The new multi-modular ICT solution studied includes automatic incorporation of data through QR labels, the safe management of the administrative and technical documentation needed by all the members of the supply chain for a safe and secure TDG, the tracking of the freight and the suggestion of routes with low risk for the environment.

The IAM-ICT methodology was applied in the design of this new ICT solution for the TDG, used as a case study, and the results show that of a total of 27 barriers, 10 sum the $80 \%$ of the total weight and it is these on which the designers and software developers of this type of solutions should focus. This study shows that the standardisation of communication platforms used by each agent of the supply chain (C111) and the compatibility with existing ICT solutions (C121) are major barriers to implementing ICT solutions. This was confirmed during the two co-creation sessions. The co-creation sessions showed that different scenarios arise for both SMEs and large companies, and so the management solution designed for the TDG should be flexible and adaptable to the needs of each user. The multi-modular design developed allows potential customers to select only those modules useful for them, increasing the flexibility of the product which would fit the needs of the users. The analysis of both scenarios (implementation in SMEs or in large companies) leads to the conclusion that i) in the case of SMEs, their lack of influence over the supply chain to enable the successful implementation of platforms sharing relevant information for the TDG is one of the main drawbacks, so the leading member for the implementation of new ICT solutions should be the transportation companies which have stronger influence over them. By contrast, ii) large companies can lead the change in their supply chain but the integration of these new ICT solutions inside their existing ERP systems is the main handicap.

In order to set the robustness of the methodology, further developments should focus on a sensitivity analysis through the application of the IAM-ICT methodology to SMEs and large companies separately, determining how it affects key factors and their hierarchy. It is also necessary to develop and apply a method to measure the efficiency of the methodology. 


\section{Additional files}

Additional file 1: AHP matrices and local and global weights for each barrier. (XLSX $20 \mathrm{~kb})$

Additional file 2: Calculation of quantifiable barriers from $B N$ results. (XLSX $13 \mathrm{~kb})$

\section{Acknowledgements}

The authors thank all the participants in the focus group and workshops for their contributions and the support of their companies, especially BP Oil, PPG Iberica, TIBA (Grupo Romeu), Infoport, Transportes Corfran and Logitren Ferroviaria.

\section{Funding}

The work presented in this paper was partially funded by CDTI (Centro de Desarrollo Tecnológico Industrial) within the INNOGLOBAL call with reference EXP00100233/INNO-20171024 and in the framework of a EUREKA project (E!11217-gADGeTs). CDTI gave financial and economic-technical assessment of the tasks developed in the project. Paper translation was cofunded by the European Regional Development Funds.

\section{Availability of data and materials}

The datasets supporting the conclusions of this article are included within the article and its additional files.

\section{Authors' contributions}

The coordination of the research and the selection of the methodology in each step of the work were driven by GDM. AK was responsible for the development of the literature review and the selection of the appropriate UDI (user driven innovation) technique in each stage. GDM, SP-R and MM conducted the UDI techniques in the first stage (workshop and LEGO serious play). The second stage UDI technique (the Focus Group), requiring the participation of experts from different disciplines, was conducted by GDM, FES, SP-R, AK and SA-N. After the identification of the barriers for the ICT implementation by applying these UDI techniques in 2 stages, these barriers were hierarchized by using 2 methods: AHP and Bayesian networks. The application of the AHP methodology to hierarchize all not quantifiable barriers was carried out by GDM, FES and SP-R; while the analysis by Bayesian networks to hierarchize quantifiable barriers was driven by FES and SA-N. The co-creation of the final prototype in a SME and a large company was conducted by GDM, FES and SP-R. All authors contributed to the development of this manuscript. All authors read and approved the final manuscript.

\section{Competing interests}

The authors declare that they have no competing interests.

\section{Publisher's Note}

Springer Nature remains neutral with regard to jurisdictional claims in published maps and institutional affiliations.

\section{Author details}

'AITEC, Parque Tecnológico, C/ Charles Robert Darwin, 20, Paterna, 46980 Valencia, Spain. ${ }^{2}$ PRISMA solutions, Klostergasse 18, 2340 Mödling, Austria. ${ }^{3}$ Universidad Europea de Madrid, Calle Tajo, s/n, 28670 Villaviciosa de Odón, Madrid, Spain. ${ }^{4}$ Universitat Politècnica de València, Camino de Vera, s/n, 46022 Valencia, Spain

\section{Received: 6 June 2018 Accepted: 16 April 2019}

\section{Published online: 11 June 2019}

\section{References}

1. Eurostat (2016). Road freight transport by type of goods in the European Union (EU). http://ec.europa.eu/eurostat/statistics-explained/index.php/ Road_freight_transport_by_type_of_goods. Accessed 4 Sept 2017.

2. Cefic (2016). Facts \& figures 2016 of the European chemical industry. https:// files.vogel.de/vogelonline/vogelonline/files/8494.pdf.

3. European Commission (2017) Report from the commission to the European parliament and the council on the application by the member states of council directive 95/50/EC on uniform procedures for checks on the transport of dangerous goods by road. https://ec.europa.eu/transparency/
regdoc/rep/1/2017/EN/COM-2017-112-F1-EN-MAIN-PART-1.PDF. Accessed 4 Sept 2017.

4. Coronado Mondragon, A. E., Lalwani, C. S., Coronado Mondragon, E. S., \& Coronado Mondragon, C. E. (2009). Facilitating multimodal logistics and enabling information systems connectivity through wireless vehicular networks. International Journal of Production Economics, 122(1), 229-240. https://doi.org/10.1016/j.ijpe.2009.05.023.

5. Perego, A., Perotti, S., \& Mangiaracina, R. (2011). ICT for logistics and freight transportation: A literature review and research agenda. International Journal of Physical Distribution \& Logistics Management, 41(5), 457-483. https://doi. org/10.1108/09600031111138826.

6. Pokharel, S. (2005). Perception on information and communication technology perspectives in logistics. Journal of Enterprise Information Management, 18(2), 136-149. https://doi.org/10.1108/17410390510579882.

7. Voordijk, H., Meijboom, B., \& De Haan, J. (2006). Modularity in supply chains: A multiple case study in the construction industry. International Journal of Operations \& Production Management, 26(6), 600-618. https://doi.org/10. 1108/01443570610666966

8. Hölttä-Otto, K., Otto, K. N., \& Simpson, T. W. (2014). Defining modules for platforms: An overview of the architecting process. In Advances in product family and product platform design (pp. 323-341). New York: Springer New York. https://doi.org/10.1007/978-1-4614-7937-6_13.

9. Baldwin, C. Y., \& Clark, K. B. (2006). Modularity in the design of complex engineering systems. In Complex engineered systems (pp. 175-205). Berlin: Springer. https://doi.org/10.1007/3-540-32834-3_9.

10. Harris, I., Wang, Y., \& Wang, H. (2015). ICT in multimodal transport and technological trends: Unleashing potential for the future. International Journal of Production Economics, 159, 88-103. https://doi.org/10.1016/j.jpe. 2014.09.005.

11. Marchet, G., Perego, A., \& Perotti, S. (2009). An exploratory study of ICT adoption in the Italian freight transportation industry. International Journal of Physical Distribution and Logistics Management, 39(9), 785-812. https://doi. org/10.1108/09600030911008201

12. Garcia-Alcaraz, J. L, Maldonado-Macias, A. A, Alor-Hernandez, G, \& SanchezRamirez, C. (2017). The impact of information and communication technologies (ICT) on agility, operating, and economical performance of supply chain. Advances in Production Engineering \& Management, 12(1), 29 40. https://doi.org/10.14743/apem2017.1.237.

13. Sternberg, H., Prockl, G., \& Holmström, J. (2014). The efficiency potential of ICT in Haulier operations. Computers in Industry, 65(8), 1161-1168. https:// doi.org/10.1016/j.compind.2014.07.002.

14. Piplani, R., Pokharel, S., \& Tan, A. (2004). Perspectives on the use of information Technology at Third Party Logistics Service Providers in Singapore. Asia Pacific Journal of Marketing and Logistics, 16(1), 27-41. https://doi.org/10.1108/13555850410765113.

15. Hollenstein, H. (2004). Determinants of the adoption of information and communication technologies (ICT): An empirical analysis based on firm-level data for the Swiss business sector. SCED, 15(3), 315-342. https://doi.org/10. 1016/j.strueco.2004.01.003

16. Jakobs, K., Pils, C., \& Wallbaum, M. (2001). Using the internet in transport logistics - The example of a track and trace system. In International conference on networking (pp. 194-203).

17. Zeimpekis, V., \& Giaglis, G. M. (2006). Urban dynamic real-time distribution services. Journal of Enterprise Information Management, 19(4), 367-388.

18. Proudlock, M. (1999). IT adoption strategies: Best practice guidelines for professional SMEs. Journal of Small Business and Enterprise Development, 6(3), 240-252.

19. Diabat, A., Khreishah, A., Kannan, G., Panikar, V., \& Gunasekaran, A. (2013). Benchmarking the interactions among barriers in third-party logistics implementation. Benchmarking: An International Journal, 20(6), 805-824. https://doi.org/10.1108/BIJ-04-2013-0039.

20. Davies, I., Mason, R., \& Lalwani, C. (2007). Assessing the impact of ICT on UK general haulage companies. International Journal of Production Economics, 106, 12-27. https://doi.org/10.1016/j.ijpe.2006.04.007.

21. Patterson, K. A., Grimm, C. M., \& Corsi, T. M. (2003). Adopting new technologies for supply chain management. Transportation Research Part E: Logistics and Transportation Review, 39(2), 95-121. https://doi.org/10.1016/S1366-5545(02)00041-8.

22. Golob, T. F., \& Regan, A. C. (2002). Trucking industry adoption of information technology: A structural multivariate probit model by trucking industry adoption of information technology: A structural multivariate probit model. Transportation Research Part C, 10, 205-228. https://doi.org/10.1016/S0968090X(02)00006-2. 
23. Chapman, R. L., Soosay, C., \& Kandampully, J. (2002). Innovation in logistic services and the new business model: A conceptual framework. Managing Service Quality, 12(6), 358-371. https://doi.org/10.1108/09604520210451849.

24. Gunasekaran, A., Subramanian, N., \& Papadopoulos, T. (2017). Information technology for competitive advantage within logistics and supply chains: A review. Transportation Research Part E: Logistics and Transportation Review, 99, 14-33. https://doi.org/10.1016/j.tre.2016.12.008.

25. Jacobsson, S., Arnäs, P. O., \& Stefansson, G. (2017). Access Management in Intermodal Freight Transportation: An explorative study of information attributes, actors, resources and activities. Research in Transportation Business \& Management, 23, 106-124

26. Helo, P., \& Szekely, B. (2005). Logistics information systems: An analysis of software solutions for supply chain co-ordination. Industrial Management and Data Systems, 105(1), 5-18. https://doi.org/10.1108/ 02635570510575153.

27. Kärkkäinen, M., Ala-Risku, T., \& Främling, K. (2004). Efficient tracking for shortterm multi-company networks. International Journal of Physical Distribution \& Logistics Management, 34(7), 545-564. https://doi.org/10.1108/ 09600030410552249

28. European Space Agency. (1991). ESA software engineering standards, ESA publications division (2nd ed.). Noordwijk: ESTEC ISSN 0379-4059.

29. Hunt, J. (2006). Agile software construction; London (1st ed.). London: Springer-Verlag ISBN 9781852339449.

30. Droschl, G., Kuhn, W., Sonneck, G., \& Thuswald, M. (2002). Assessing the practical benefits of formal methods for software development. Safety Science, 40, 719-730. https://doi.org/10.1016/S0925-7535(01)00082-0.

31. Tseng, M.-L., Wu, K.-J., \& Nguyen, T. T. (2011). Information technology in supply chain management: A case study. Procedia-Social and Behavioral Sciences, 25, 257-272. https://doi.org/10.1016/j.sbspro.2011.10.546.

32. Kengpol, A., \& Tuominen, M. (2006). A framework for group decision support systems: An application in the evaluation of information technology for logistics firms. International Journal of Production Economics, 101(1), 159-171. https://doi.org/10.1016/j.jpe.2005.05.013.

33. Bouzon, M., Govindan, K., Rodriquez, C. M. T., \& Campos, L. M. S. (2016) Identification and analysis of reverse logistics barriers using fuzzy Delphi method and AHP. Resources, Conservation and Recycling, 108, 182-197. https://doi.org/10.1016/j.resconrec.2015.05.021.

34. Carrizo, D., Dieste, O., \& Juristo, N. (2014). Systematizing requirements elicitation technique selection. Information and Software Technology, 56(6), 644-669.

35. Kristiansen, P., \& Rasmussen, R. (2014). Building a better business using the Lego serious play method. Hoboken: Wiley.

36. Hammerschmidt R (2013) ASSIST - assessment and evaluation tools for telemedicine, Bonn, Germany. https://gsp.esa.int/documents/10192/ 43064675/C4200023001ExS.pdf/b0fd25a6-6863-45db-9bca-930dedb802b2.

37. Cooper, G. F., \& Herskovits, E. (1992). A Bayesian method for the induction of probabilistic networks from data. Machine Learning, 9, 309-347.

38. Santarremigia, F. E., Molero, G. D., Esclapez, M. D., \& Awad-Núñez, S. (2017) Total management tool oriented to carbon footprint reduction in terminals of containers. In F. W. Gianluca Dell'Acqua (Ed.), Transport infrastructure and systems: Proceedings of the AllT international congress on transport infrastructure and systems (pp. 987-995). London: CRC Press, Taylor \& Francis Group, LLC ISBN 9781138030091.

39. Reynolds, S. J., Schultz, F. C., \& Hekman, D. R. (2006). Stakeholder theory and managerial decision-making: Constraints and implications of balancing stakeholder interests. Journal of Business Ethics, 64(3), 285-301. https://doi. org/10.1007/s10551-005-5493-2.

40. Clarkson, M. (1999). Principles of stakeholder management. The Clarkson principles (pp. 4-8). Toronto: The Clarkson Centre for Business Ethics.

41. Saaty, T. L. (1980). The analytic hierarchy process, planning, priority setting, resource allocation. New York: McGraw-Hill.

42. Okoli, C., \& Pawlowski, S. D. (2004). The Delphi method as a research tool: An example, design considerations and applications. Information \& Management, 42(1), 15-29. https://doi.org/10.1016/j.im.2003.11.002.

43. Santarremigia, F. E., Molero, G. D., Poveda-Reyes, S., \& Aguilar-Herrando, J. (2018). Railway safety by designing the layout of inland terminals with dangerous goods connected with the rail transport system. Safety Science, 110, 206-216. https://doi.org/10.1016/j.ssci.2018.03.001

44. Saaty, T. L. (2006). The analytic network process. In Decision making with the analytic network process. International series in operations research \& management science (Vol. 95). Boston: Springer. https://doi.org/10.1007/0387-33987-6 1.

45. Saaty, T. L., \& Ozdemir, M. S. (2003). Why the magic number seven plus or minus two. Math Comput Model, 38(3-4), 233-244. https://doi.org/10.1016/ S0895-7177(03)90083-5.

46. Backbaus, J. (1980). The Pareto principle. Analyse \& Kritik, 2(2), 146-171. https://doi.org/10.1515/auk-1980-0203.

47. Koch, R. (2004). Living the $80 / 20$ way. Melbourne: Nicholas Brealey Publication.

\section{Submit your manuscript to a SpringerOpen ${ }^{\circ}$ journal and benefit from:}

- Convenient online submission

- Rigorous peer review

- Open access: articles freely available online

- High visibility within the field

- Retaining the copyright to your article

Submit your next manuscript at $\boldsymbol{\nabla}$ springeropen.com 